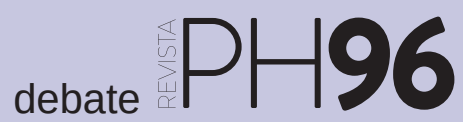

\title{
La memoria franquista en el espacio urbano. Cuestiones metodológicas e historiográficas para las comisiones locales de memoria histórica
}

César Rina Simón | Dpto. de Historia, Universidad de Extremadura

URL de la contribución <www.iaph.es/revistaph/index.php/revistaph/article/view/4275>

El espacio urbano está plagado de significaciones, de marcadores de identidad. Nuestra sociedad construye su memoria en diálogo constante con un espacio repleto de simbolismo. Monumentos, banderas, iconos, funcionalidad de los edificios, imaginarios locales y el nomenclátor actúan como recordadores o propiciadores de lo que se debe recordar. En los regímenes políticos contemporáneos, el sentido, forma y significado de estos marcadores viene determinado por las instituciones, que oficializan determinadas narrativas del pasado y hacen de su uso público uno de los principales referentes en la construcción de su legitimidad. De hecho, una de las constantes históricas de los dos últimos siglos ha sido el combate político por construir lugares de memoria y hacer de la calle un lienzo en el que transmitir valores, ideologías o lecturas del pasado. Estas cuestiones han sido centrales en los debates historiográficos de las últimas décadas a partir de los trabajos pioneros de Josefina Cuesta, Paloma Aguilar, Elizabeth Jelin —para el caso argentino- o Pierre Nora -para el francés-.

Si aceptamos la caracterización del espacio como constructor y fijador de la memoria colectiva, no podemos mirar para otro lado a la hora de realizar una lectura crítica de los símbolos aún visibles de la dictadura franquista, desde el momento en que como colectivo que se reafirma en unos valores democráticos y constitucionales hemos construido sus imaginarios desde la oposición al franquismo. No es posible desligar la práctica historiográfica del horizonte de las ideologías y del compromiso con determinado modelo de sociedad. Por eso mismo, ante la dificultad de establecer criterios funcionales de valoración de lo que es "memoria franquista" o no, se hace necesario abrir un debate social e his- toriográfico que trascienda del componente polemizador de los medios de comunicación y se enfrente a la lectura y resignificación del espacio urbano. La memoria ha sido una temática muy escurridiza para el oficio de historiador, sin embargo, éste puede aportar herramientas: manejo de fuentes y archivos, la experiencia metodológica y los conocimientos conceptuales precisos para participar en la localización de aquellos lugares de la memoria de la dictadura. La tarea no es fácil, en tanto que muchos de estos elementos han sido resignificados o bien han perdido su halo franquista. No es contradictorio, por tanto, el ejercicio de la historia como disciplina de la participación en los procesos de redefinición de la memoria colectiva en clave democrática.

Esta memoria se presenta en España de forma fragmentada. A diferencia del caso italiano, alemán o portugués, donde la construcción democrática se hizo desde una derrota o una revolución, la peculiaridad de la transición española radica en que se sustentó en un pacto en el que eran compatibles diferentes memorias siempre que su proyección no afectara al nuevo constructo político. Al no producirse una ruptura drástica con el pasado, la memoria de la dictadura se entrelaza con todo tipo de recuerdos relacionados con la violencia y la represión pero también con el desarrollismo, la paz social o la resistencia al comunismo. La primera entrada de Franco en el Diccionario biográfico de la Real Academia de la Historia constata la pervivencia de esta imagen de dictador benigno. Al mismo tiempo, al pervivir en algunas culturas políticas españolas memorias complacientes con el franquismo, el silencio, el olvido y no la reparación son defendidas en el debate mediático por grupos que en cierta medida hunden sus raíces en la dictadura. 
a debate Memoria democrática en la construcción de la historia y el patrimonio

| coordina Josefina Cuesta Bustillo

Una vez aprobada a nivel estatal la Ley de la Memoria Histórica 52/2007 de 26 de diciembre, y completada a nivel regional por algunas autonomías, se ha abierto el debate sobre cómo gestionar la memoria colectiva de la dictadura que aún pervive en nuestro espacio urbano. Han sido creadas centenares de comisiones municipales cuyo trabajo ha consistido en rastrear estos marcadores y realizar informes de cara a una posible revisión, que habría que abordar desde múltiples ópticas sociales. El trabajo de estas comisiones ha sido complejo. En primer lugar, por los espacios en los márgenes que la ley no recoge -fue anterior a la práctica de estas comisiones, pero no así a la trayectoria de numerosas asociaciones para la recuperación de la memoria histórica-. A su vez, la dictadura franquista, con su capacidad camaleónica para sobrevivir a diferentes contextos internacionales y por su longevidad, dificulta la labor de identificación de su memoria. No podemos olvidar que buena parte de los forjadores de nuestro sistema político actual provenían de las altas instancias de la dictadura, lo que impide focalizar el recuerdo en un período específico de cada personaje. El caso de Adolfo Suárez ejemplifica estas dificultades.

En estas páginas pretendo plantear algunos de los problemas teórico-metodológicos que hemos tenido los miembros de la Comisión para la revisión del callejero urbano y aplicación de la Ley de la Memoria Histórica del Ayuntamiento de Cáceres, integrada por cuatro historiadores: Fernando Jiménez Berrocal -jefe del Archivo Municipal y cronista-, María Jesús Criado -presidenta de la Asociación Memorial en el Cementerio de Cáceres, AMECECA-, José Hinojosa Durán -coordinador del Grupo de Estudios de Historia Contemporánea de Extremadura, GEHCEX-y el que firma estas páginas -profesor de Historia Contemporánea en la Universidad de Extremadura-. Los trabajos se prolongaron entre marzo de 2017 y febrero de 2018. El objetivo es participar en el debate historiográfico y social sobre qué hacer con la memoria del franquismo, cómo abordarla y cómo construir una memoria democrática a partir de una experiencia concreta. Como ha señalado recientemente Jesús Izquierdo Martín (Ayer, n. ${ }^{0} 111,2018$ ), el desafío de la memoria abre el horizonte interpretativo a modelos normativos o plurales cuyo debate será abordado a medida que avancen las comisiones locales para la identificación de los imaginarios franquistas. Los principales "puntos ciegos" de la Ley de Memoria Histórica fueron los siguientes:

$>$ Cruz de los caídos. Principal monumento franquista en la mayoría de municipios. Muchas fueron retiradas pero otras tantas perviven. No cabe duda de su significación franquista para conmemorar a los mártires del nacionalcatolicismo y a los caídos del fascismo. Durante la transición se cambió el rótulo "A LOS HIJOS DE ESTA CIUDAD QUE DIERON SU VIDA POR ESPAÑA, UNA GRANDE Y LIBRE. 18 DE JULIO DE 1936. ¡ARRIBA ESPAÑA! ¡SALUDO A FRANCO!" por el genérico "a la memoria de sus hijos muertos por la patria." De esta forma, al cambiar el mensaje, se pretendió resignificar el símbolo. Sin embargo, el emblema tenía tantas connotaciones franquistas que durante décadas ha seguido siendo el punto neurálgico de los nostálgicos de la dictadura. En la actualidad, desprovistas de esa impronta, perduran en los centros neurálgicos de ciudades y pueblos. En el seno de la comisión, no había duda de que se trataba de un fósil de la memoria franquista y más cuando a petición municipal, en 1938, se insistió en que tuviera una planta y unos perfiles visiblemente fascistas. Fue inaugurada por Pilar Primo de Rivera con todo el aparato ritual nacionalcatólico y fascista. Sin embargo, el planteamiento de su retirada ha generado un amplio debate público, alegando los defensores de su permanencia que una cruz es un símbolo cristiano, no franquista. En este sentido, los perfiles entre catolicismo y dictadura se difuminaron tanto que la valoración de todo tipo de símbolos o nomenclátor religioso resulta compleja para cualquier comisión con estos fines. En el caso que nos atañe, no cabe duda de su contenido y continente franquista.

$>$ Placas conmemorativas de cualquier hazaña o efeméride con mensajes eminentemente informativos sin presencia explícita de exaltación del régimen. También levantaron revuelo mediático, en tanto que se consideraban marcadores históricos de un acontecimiento, no políticos, y por tanto su retirada contradecía el espí- 
ritu de "recuperación de la memoria." Discernir entre la memoria franquista y la memoria aséptica, en un régimen político que asentó su modelo de legitimidad en la omnipresencia de prácticas y narrativas de exaltación totales, es tarea ardua complicada. Conviene contrarrestar los discursos ideológicos que rechazan la limpieza del callejero franquista, al que consideran un aséptico marcador del pasado. Estas posturas suelen ignorar los procesos constantes de reconstrucción simbólica del espacio urbano y, en la mayoría de los casos, esta defensa historicista del imaginario franquista desde el plano científico social esconde la perpetuación implícita de la memoria de la dictadura.

> Nomenclátor de las élites culturales de la dictadura, incluso casos en los que el nombre se puso en período democrático. Esta cuestión cronológica los deja al margen de Ley de Memoria Histórica, por lo que cabría abrir sus consideraciones también a la memoria franquista construida en democracia. En este punto, las comisiones encontramos un fuerte escollo a la hora de valorar el nomenclátor de artistas, periodistas o escritores que desenvolvieron su trabajo en actitud de connivencia con la dictadura o que incluso formaron parte de la estructura de estado, si bien su nombramiento respondió a méritos del ámbito cultural. Al respecto, los matices son inabarcables, y van desde el periodista José Ibarrola, autor de textos de exaltación de la represión en la prensa extremeña, a Angelita Capdevielle, líder de la Sección Femenina y con un papel destacado en la sociabilización del régimen pero cuyo reconocimiento tiene relación con su labor de recuperación del folklore regional, pasando por el alcalde Alfonso Díaz de Bustamante o Antonio Floriano Cumbreño, archivero y director del diario Falange. Podríamos marcar como pauta selectiva su participación activa y comprometida con el alzamiento y la dictadura, pero aun así cada casuística desbordaría la clasificación. Además, la participación en las altas estructuras del Estado deja de ser argumento en el momento en que muchos de estos personajes tuvieron una rápida conversión a los principios democráticos y constitucionales e incluso lideraron la Transición. Tampoco puede ser tomada en cuenta la afiliación a FET y las JONS, pues era prerrogativa de la escala de funcionarios. No en pocas ocasiones, muchos personajes con espacio en la memoria pública adaptaron sus afinidades políticas a los diferentes contextos y modelos de Estado, pasando algunos por fervientes republicanos, franquistas y demócratas en la misma biografía.

$>$ Nomenclátor historicista. El franquismo construyó su hegemonía desde una continuidad histórica -esencial, tradicional y religiosa - que enraizaba la dictadura con una serie de hitos históricos que la conectaban con el Imperio. Es por ello que fueron frecuentes denominaciones como Reyes Católicos. Es evidente el contenido político-historicista de este nomenclátor, pero consideramos que no puede ser materia de revisión en el espacio urbano, en tanto que forma parte de narrativas del pasado polisémicas. Cuestión diferente son las calles

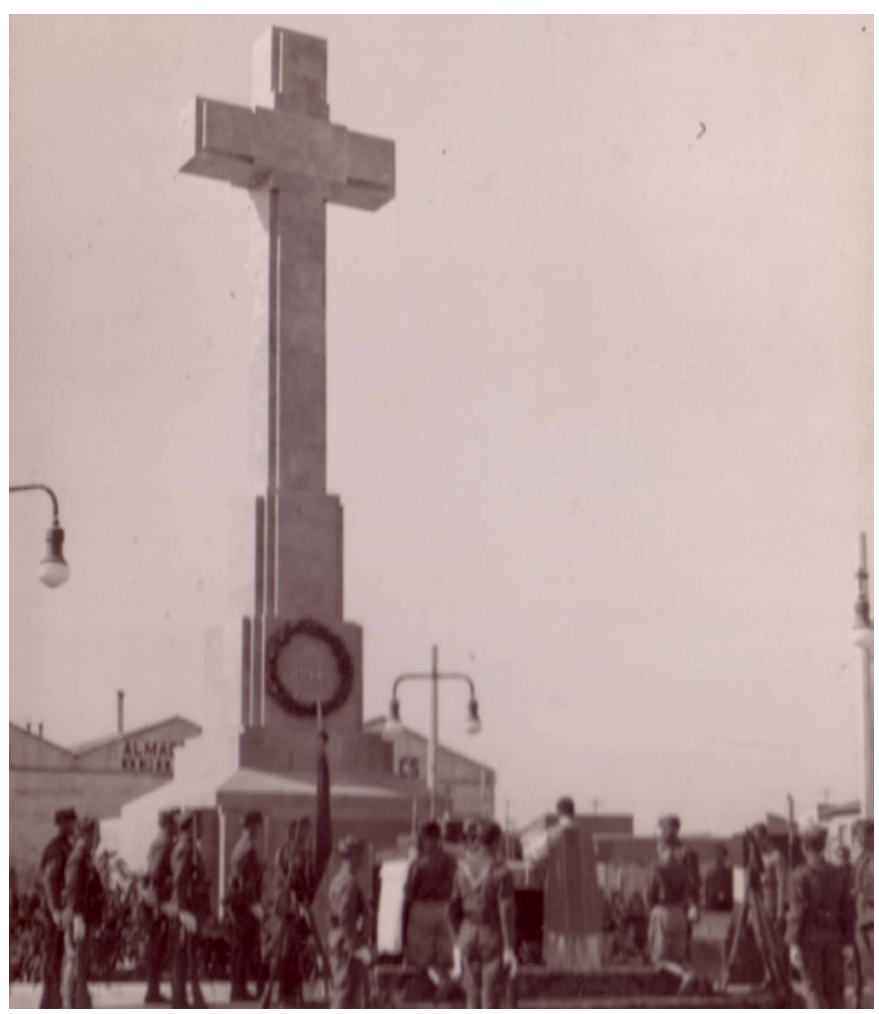

Jura de bandera Alféreces Provisionales ante la cruz de los caídos, 16 octubre 1938 | fuente Archivo Histórico Municipal de Cáceres 
a debate Memoria democrática en la construcción de la historia y el patrimonio

| coordina Josefina Cuesta Bustillo

dedicadas a personajes más cercanos históricamente al alzamiento, aunque fallecieron antes del 18 de julio, pero que fueron referentes fundacionales de los imaginarios franquistas. Nos referimos en el caso cacereño a Miguel Primo de Rivera, al que se le dedicó una calle en la década de los cuarenta para contentar de una vez al ejército, a las élites conservadoras y a Falange, y a José Calvo Sotelo, el protomártir de la dictadura, usado como símbolo legitimador de la sublevación. Ambos no son personajes del franquismo, pero sí su uso como referentes de la memoria franquista.

> Marcadores con múltiples significaciones según contextos. Determinadas instituciones tuvieron un papel destacado en la construcción de imaginarios franquistas, como es el caso del Regimiento Argel, responsable del alzamiento militar en Cáceres. Sin embargo, el significado de su monumento, además de por el cambio de placa, adquiere diversas lecturas, al tratarse de una institución con raigambre en la ciudad. En su origen, su erección tuvo un carácter eminentemente franquista, "dedicado al heroico comportamiento que ha tenido en el pasado Glorioso Movimiento Nacional", pero la suma de diversas memorias y olvidos en la comunidad lo convierten en un referente espacial con múltiples lecturas. En el espacio urbano entran en conflicto diferentes memorias que coexisten en el mismo tiempo y resulta complejo determinar su impronta franquista en el presente, no así en el pasado, ya que el monumento tuvo una dimensión clara de exaltación del alzamiento. Podemos comentar a su vez el nomenclátor dedicado a Alemania, Italia y Portugal, homenajes a los apoyos internacionales de la dictadura pero desprovistos en la actualidad de dicha significación. Cabría por último señalar las calles dedicadas a las victorias militares franquistas, cuyo nombre hoy en día hace referencia a un espacio geográfico o a una ciudad y no a un hito bélico.

$>$ Nomenclátor religioso. Este asunto es complejo para cualquier comisión, en tanto que suele hacer referencia a espacios ocupados por iglesias o conventos y, por tanto, son referentes precontemporáneos que la dictadura solo restituyó. O bien, nombramientos exnovo, cuyo fin fue arraigar a la dictadura con referentes de la cultura y de la religiosidad popular, pero cuyos términos y significantes trascienden con creces al franquismo.

Estos seis amplios interrogantes nos reafirman en la necesidad de profundizar en debates concretos en torno a la memoria y el olvido de la Guerra Civil y de la dictadura, superando la dialéctica a favor o en contra para preguntarnos qué y cómo recordar. El trabajo de las comisiones para la aplicación de la Ley de la Memoria Histórica ha localizado múltiples puntos de fuga a la hora de identificar qué es o no es memoria franquista. Así mismo, convendría poner en común los informes de dichas comisiones con el objetivo de reconocer problemas comunes o fallas en la ley, abrir los horizontes historiográficos a la labor desempeñada por las asociaciones para la recuperación de la memoria histórica desde la muerte del dictador e incluso llegar a establecer una guía metodológica que afronte estos interrogantes. No cabe duda que los símbolos y los mensajes que emite nuestro espacio urbano son polisémicos y su significados variables y coyunturales, lo que dificulta aún más los consensos, y más cuando coexisten con la memoria democrática otras de impronta nacionalcatólica.

En último término, la supervivencia cuarenta años después de marcadores simbólicos, monumentos y nomenclátor franquista constata las debilidades de las memorias democráticas. Si bien la aprobación de leyes de memoria histórica han contribuido a generalizar estos debates, sigue siendo necesario, también desde la historiografía, participar de la construcción de memorias que fortalezcan consensos e imaginarios democráticos en torno a un pasado que es siempre llamado por el presente y proyectado hacia el futuro. Tradicionalmente, la historiografía, y el resto de ciencias sociales, ha tenido una relación de alteridad con los usos normativos del pasado, relativizando nuestra capacidad profesional para convertirnos en jueces. Sin embargo, los procesos abiertos de redifinición del espacio urbano nos invitan a participar como gestores especializados de archivos, fuentes y testimonios, con el fin de contribuir con la construcción de una memoria colectiva asentada sobre pilares democráticos. 